\title{
Individual Differences in Amphetamine Self-Administration: The Role of the Central Nucleus of the Amygdala
}

\author{
Mary E Cain*,', Emily D Denehy ${ }^{2}$ and Michael T Bardo ${ }^{2}$ \\ 'Department of Psychology, Kansas State University, Manhattan, KS, USA; '2Department of Psychology, University of Kentucky, Lexington, \\ KY, USA
}

\begin{abstract}
Rats categorized as high responder (HR), based on their activity in an inescapable novel environment, self-administer more amphetamine than low responder (LR) rats. The current study examined if the central nucleus of the amygdala (ACe) contributes to the elevated response for amphetamine in HR rats. Male Sprague-Dawley rats were classified as HR and LR rats based on their activity in inescapable novelty and novelty place preference, and then were trained to self-administer amphetamine $(0.1 \mathrm{mg} / \mathrm{kg} / \mathrm{infusion})$. Once stable responding was achieved, rats received microinfusions of the $\mathrm{GABA}_{A}$ agonist muscimol $(0.5 \mu \mathrm{g} / 0.5 \mu \mathrm{l})$ or phosphate-buffered saline into the ACe immediately before self-administration of amphetamine $(0.1,0.03,0.01$, or $0.001 \mathrm{mg} / \mathrm{kg} / \mathrm{infusion})$ or saline. An additional group of rats was trained to lever press for sucrose rather than amphetamine. Based on the inescapable novelty test, HR rats self-administered more amphetamine than $L R$ rats at the 0.03 and $0.01 \mathrm{mg} / \mathrm{kg} /$ infusion unit doses; there were no significant individual differences in amphetamine self-administration based on the novelty place preference test. Inactivation of the ACe with muscimol decreased selfadministration at the 0.03 and $0.01 \mathrm{mg} / \mathrm{kg} /$ infusion unit doses in HR rats, but had no effect on $\mathrm{LR}$ rats. ACe inactivation had no reliable effect on inactive lever responding and appeared to be region specific based on anatomical controls. In addition, while inactivation of the ACe decreased responding for sucrose, inactivation did not differentially affect HR and LR rats. These results suggest that the ACe contributes to the elevated rate of amphetamine self-administration in HR rats.

Neuropsychopharmacology (2008) 33, | |49-| | 61; doi: I0.1038/sj.npp. I 30|478; published online I3 June 2007
\end{abstract}

Keywords: amphetamine; central nucleus of the amygdala; individual differences; inescapable novelty; muscimol; self-administration

\section{INTRODUCTION}

Personality traits may contribute to individual differences in drug-abuse vulnerability. One widely studied personality trait is 'sensation seeking' or 'novelty seeking'. Using Cloninger's novelty-seeking scale or Zuckerman's sensation-seeking scale, high-novelty seekers have been shown to use drugs more frequently than low-novelty seekers (Donohew et al, 1991; Wills et al, 1994, 1998; Zuckerman, 1994). Animal models have been developed to examine the correlation between novelty seeking and drug use. One widely used animal model is the novelty 'responder' test in which rats are categorized as either high responder (HR) or low responder (LR) based on a median split of the amount of locomotor activity displayed in an inescapable novel environment (Piazza et al, 1989). HR rats are more sensitive than LR rats to amphetamine-induced locomotor activity (Piazza et al, 1989; Hooks et al, 1991; Exner and Clark, 1993;

\footnotetext{
*Correspondence: Professor ME Cain, Department of Psychology, Kansas State University, 469 Bluemont Hall, I 100 Mid-Campus Drive, Manhattan, KS 66506-5302, USA, Tel: + I 785532 6884, Fax: + I 785 5325401, E-mail: mecain@ksu.edu

Received 16 February 2007; revised 8 May 2007; accepted I4 May 2007
}

Gingras and Cools, 1997) and to amphetamine selfadministration (Piazza et al, 1989; Pierre and Vezina, 1997; Klebaur et al, 2001).

While there is now ample evidence to support the notion that individual differences in activity in inescapable novelty predict drug self-administration, the biological substrates contributing to these differences are not known fully. One mechanistic explanation is that HR rats may have greater sensitivity in the mesolimbic dopamine system than LR rats. In support of this hypothesis, HR rats exhibit greater accumbal dopamine (DA) release following either inescapable novelty or stimulant drugs (Bradberry et al, 1991; Piazza et al, 1991b). In addition, HR rats have greater DA uptake, greater cocaine-evoked DA release (Chefer et al, 2003), and greater firing rates and bursting activity in DA neurons than LR rats (Marinelli and White, 2000), suggesting that the responsiveness of DA neurons in HR rats may account for the enhanced responsiveness to novelty and psychostimulants. Another mechanistic explanation may be related to individual differences in levels of the stress hormone corticosterone (Cador et al, 1993; Piazza and Le Moal, 1998). HR rats have a longer duration of corticosterone secretion after exposure to a novel environment (Piazza et al, 1991a) and higher levels of corticotrophin releasing hormone in the paraventricular nucleus of 
the hypothalamus (Kabbaj et al, 2000). Since glucocorticoids have the ability to stimulate DA release (Piazza et al, 1993), it is also possible that the interaction between DA and corticosterone contribute to these individual differences.

It has been argued that free-choice novelty preference may be a better index of 'novelty seeking' than activity in inescapable novelty (Bardo et al, 1996). In this test, rats are allowed free-choice access to both novel and familiar stimuli. When rats enter a novel compartment from a familiar compartment, there is a transient and rapid surge in accumbal DA activity (Rebec et al, 1997). Using freechoice novelty preference tests, high-novelty-seeking rats have been shown to be more sensitive than low-noveltyseeking rats to amphetamine-conditioned place preference (Robinet et al, 1998; Klebaur and Bardo, 1999). However, rats classified as high- or low-novelty seekers based on a median split of novelty place preference scores do not differ in amphetamine self-administration (Klebaur et al, 2001; Cain et al, 2004); however, see Cain et al (2005). Further, in contrast to activity in inescapable novelty, free-choice novelty does not result in corticosterone release (Misslin et al, 1982), suggesting that the specific ability of activity in inescapable novelty to predict amphetamine self-administration may depend on individual differences in glucocorticoid release by the hypothalamic-pituitary-adrenocortical axis (HPA).

The amygdala has been identified as a focal point for activation of the HPA axis (Beaulieu et al, 1986), and the central nucleus of the amygdala (ACe) in particular is known to have a role in arousal (Davis and Whalen, 2001; Kapp and Cain, 2001) and response to novelty (McEchron et al, 1995; Kapp et al, 1997). The ACe is comprised of two extended components, the medial-extended amygdala and the central-extended amygdala (Alheid and Heimer, 1988; Heimer et al, 1991). The cells of the central-extended amygdala continue into the reward-relevant shell of the nucleus accumbens (Alheid and Heimer, 1988; Heimer et al, 1991). While no studies to date have examined if the ACe contributes to the differential responding of $\mathrm{HR}$ and LR rats, numerous studies suggest that the ACe has a role in the rewarding effects of psychostimulants. DA neurons within the $\mathrm{ACe}$ are thought to contribute to responding for psychostimulants, as direct microinjection of amphetamine into the ACe is rewarding (Chevrette et al, 2002) and produces hyperactivity (O'Dell et al, 1999). Infusion of the $\mathrm{DA} \mathrm{D}_{1}$ antagonist SCH-23390 into the ACe (Caine et al, 1995; Alleweireldt et al, 2006) or the bed nucleus of the stria terminalis (Epping-Jordan et al, 1998) also increases cocaine self-administration, an effect that likely reflects a compensatory increase in drug intake due to a decrease in reinforcement effectiveness.

The purpose of the current study was to determine if the ACe contributes to the differential self-administration of amphetamine in rats classified as HR or LR based on activity in inescapable novelty. It was predicted that inactivation of the ACe would attenuate self-administration of amphetamine to a greater extent in HR rats than in LR rats. Muscimol, a GABA $A_{\mathrm{A}}$ agonist, was chosen to inactivate the ACe because there are a substantial number of intrinsic GABAergic neurons located within the ACe that innervate multiple brainstem projection neurons (Smith and Pare, 1994; Cassell et al, 1999).

\section{MATERIALS AND METHODS}

\section{Animals}

Adult male, Sprague-Dawley rats (175-200 g body weight) were obtained from Harlan Inc. (Indianapolis, IN), and were housed individually in standard polyurethane cages with free access to food and water. The colony room was maintained at $24^{\circ} \mathrm{C}$ and $45 \%$ humidity, with lights on 0700-1900 h. Before the start of the experiment, rats were handled and acclimated to the colony for 1 week. Behavioral testing was conducted during the light phase. Procedures were approved by the University of Kentucky Institutional Animal Care and Use Committee and conformed to the Guide for the Care and Use of Laboratory Animals (1996).

\section{Apparatus}

For measuring activity in inescapable novelty, a locomotor chamber was used consisting of a rectangular wooden box $(24.5 \times 28 \times 43 \mathrm{~cm})$ outfitted with two infrared beams mounted $3 \mathrm{~cm}$ above a metal grid floor. The walls were painted white and there was pine bedding under the floor. Beams were oriented at $90^{\circ}$ from each other and centered on each wall. Infrared detectors were linked to a personal computer and photobeam interruptions were recorded. A white-noise generator created ambient background noise $(\sim 70 \mathrm{~dB})$ to mask sound from outside the chamber. The apparatus was located in an isolated test room with overhead fluorescent illumination.

For measuring novelty place preference, a rectangular apparatus was used that had three different wooden compartments separated by removable solid partitions. The two end compartments measured $28 \times 35 \times 45 \mathrm{~cm}$, and the smaller, middle compartment measured $19 \times 10 \times 45 \mathrm{~cm}$. One end compartment had white walls, a mesh floor, and newspaper beneath the floor. The other end compartment had black walls, a metal rod floor, and pine bedding beneath the floor. The middle compartment had gray walls and a solid wood floor. During testing, the solid partitions were replaced with similar partitions containing a $10 \times 10 \mathrm{~cm}$ opening, which allowed the rats' access to all three compartments. The apparatus was located in a laboratory room separate from the colony room with a white noise generator and audio speaker (ambient background of $\sim 70 \mathrm{~dB}$ ). A video camera used to record the experimental sessions was suspended from the ceiling above the apparatus.

For sucrose-maintained responding and drug self-administration, an operant conditioning chamber (ENV-001, Med Associates, St Albans, VT) was used, which was enclosed in a sound-attenuating compartment and operated by a computer interface. On the front panel of the operant conditioning chamber was a $5 \times 4.2 \mathrm{~cm}$ opening that allowed access to a recessed food tray. Two metal response levers were located on either side of the food tray $7.3 \mathrm{~cm}$ above a metal-grid floor. A $28 \mathrm{~V}, 3-\mathrm{cm}$ diameter, white cue light was centered $6 \mathrm{~cm}$ above each response lever. Infusions were delivered via a syringe pump (Med Associates, PHM100). A water-tight swivel allowed attachment of the catheter tubing from a $10-\mathrm{ml}$ syringe to the rat inside the operant conditioning chamber. 


\section{Novelty Tests for Individual Differences}

All rats were screened by one or two 'blind' observers in two different novelty tests in the same order: (1) activity in inescapable novelty and (2) novelty place preference. The general procedures have been described previously for each test (Bevins et al, 1997; Klebaur et al, 2001).

For activity in inescapable novelty, rats were placed in the locomotor apparatus for $30 \mathrm{~min}$. Rats were classified as HR or LR based on a median split of the total photobeam breaks for the $30 \mathrm{~min}$ test.

On the day following the inescapable novelty test, each rat began the novelty place preference test. Each rat was habituated to either the white or black compartment for $30 \mathrm{~min} /$ day on each of 2 consecutive days. The compartment each rat was habituated to was counterbalanced across animals. On the third day, each rat was tested for place preference. Rats were placed in the center gray compartment and were given unrestricted access to all compartments for $15 \mathrm{~min}$. A preference ratio was calculated as the time spent in the novel end compartment divided by the sum of time in both the novel and familiar end compartments. The rat was considered to be in a compartment when both front paws were in the compartment. Rats were classified as high- or low-novelty seekers based on a median split of the place preference ratio.

\section{Amphetamine Self-Administration}

All rats were pretrained briefly to lever press on a single lever for sucrose pellets (Noyes; $45 \mathrm{mg}$ ) before intravenous drug self-administration. The rats were deprived to $85 \%$ of their ad libitum weights by restricting their intake of rat chow to $5-10 \mathrm{~g} / \mathrm{day}$ for 7 days. Subsequently, rats were trained on a fixed ratio 1 (FR-1) schedule of sucrose reinforcement for a 15-min period and were required to earn 100 reinforcers. The FR-1 schedule was increased to FR-2, FR-3, and then FR-5 (one daily session at each FR value). Following sucrose training, rats were given ad libitum access to food to regain their free-feed body weight and were maintained on ad libitum food access for the remainder of the experiment.

After recovering to free-feed body weight (approximately 7-10 days), rats were anesthetized with ketamine $(80 \mathrm{mg} / \mathrm{kg}$, IP) and diazepam $(5 \mathrm{mg} / \mathrm{kg}$, IP) and implanted with an indwelling jugular catheter and bilateral intracranial cannulae. The Silastic catheter $(0.2 \mathrm{~mm}$ i.d.; Fisher Scientific) passed under the skin to exit from a piece of stainless-steel hypodermic tubing (22 gauge). Immediately after the catheter was implanted, rats were placed into a stereotaxic instrument (Stoelting, Wood Dale, NJ) and were implanted with bilateral stainless-steel guide cannulae (26 gauge, Small Parts) fitted with 33 gauge obdurators $1.0 \mathrm{~mm}$ dorsal to the ACe (AP: -2.3 , ML: \pm 4.2 , DV: -6.5 ; Paxinos and Watson, 1998). A separate group of rats were prepared with cannula located deep in cortical layers 2 and 3 to serve as control sites (AP: +2.75 , ML: \pm 4.2 , DV: -6.5 ). The cannulae and catheter were then embedded in a cap of dental acrylic affixed to the top of the skull with four stainless-steel jeweler's screws. Catheters were flushed daily with $2 \mathrm{mg} / \mathrm{ml}$ heparinized saline $(0.1 \mathrm{ml} /$ day $)$ to maintain patency. Rats were allowed 7 days to recover before commencing amphetamine self-administration.
Following the recovery from surgery, rats were introduced to the operant-conditioning chamber for 60-min daily sessions in which responses made on one lever (active) were recorded and were followed by infusions of $0.1 \mathrm{mg} / \mathrm{kg} /$ infusion D-amphetamine sulfate (gift from the National Institute on Drug Abuse; dissolved in $0.9 \% \mathrm{NaCl}, 60 \mu \mathrm{l}$ infusion delivered over $5.9 \mathrm{~s}$ ) instead of sucrose reinforcement. A relatively high dose was chosen for initial training because previous research in our laboratory demonstrated that rats classified as HR and LR differ at low unit doses (Klebaur et al, 2001), and thus the high dose would be expected to minimize any differences in initial acquisition of responding. Responses made on the other lever (inactive) were recorded but had no programmed consequence. Each lever press initially resulted in the simultaneous activation of the infusion pump and the cue lights, which signaled a 20-s time-out period in which responding was not reinforced. The FR-1 schedule was then increased to FR-2, FR-3, and FR-5. Rats were maintained on a terminal FR-5 schedule until stable responding was achieved. Stable responding was defined as: (1) less than $20 \%$ variability in the number of infusions earned across three consecutive sessions; (2) greater than a 2:1 ratio of active: inactive lever presses; and (3) at least ten infusions per session.

\section{Intracranial Infusions}

Following three consecutive days of stable responding on the FR-5 schedule, intracranial infusions commenced. The obdurators were removed from the cannulae and stainlesssteel injection cannulae (33 gauge, Small Parts) were inserted $1 \mathrm{~mm}$ below the tip of the guide cannulae immediately before the self-administration session. The injection cannulae were connected to $10-\mu \mathrm{l}$ Hamilton syringes (Hamilton Co.) that were mounted on an infusion pump (KDS Scientific). Muscimol $(0.5 \mu \mathrm{g} / \mathrm{side})$ or phosphate-buffered saline (PBS; $\mathrm{pH}$ 7.4) was infused bilaterally at a volume of $0.5 \mu \mathrm{l} /$ side over $2 \mathrm{~min}$. This dose and volume was chosen based on previous reports (Kruzich and See, 2001; Martinez et al, 2006). The injection cannulae were left in place for $1 \mathrm{~min}$ after the infusion, at which time the injection cannulae were removed and the obdurators were replaced. Previous research has demonstrated that an intracranial infusion of muscimol can affect behavior within 5 min (Manning, 1998; Spanis et al, 1999) and lasts approximately $6 \mathrm{~h}$ (Li et al, 1999). A within-subjects design was used in which each rat received an infusion of either muscimol or PBS in a counterbalanced order across two sessions for each amphetamine dose tested.

Immediately following the intracranial infusion, rats were placed in the operant chamber and allowed to selfadminister $\mathrm{D}$-amphetamine $(0.1 \mathrm{mg} / \mathrm{kg} /$ infusion $)$ for a 60 min session. Following the initial two intracranial infusions, the dose of amphetamine was reduced to $0.03,0.01$, and $0.001 \mathrm{mg} / \mathrm{kg} /$ infusion, followed by saline substitution. Rats self-administered for three sessions at each dose and then received infusions of muscimol or PBS in a counterbalanced order across two sessions for each of the amphetamine doses tested and saline. Following the last session at the saline dose, a subset of rats $(n=10)$ were returned to the initial training and testing dose of amphetamine $(0.1 \mathrm{mg} / \mathrm{kg} /$ infusion) for three sessions and then received muscimol or 
PBS infusions in counterbalanced order during the next two sessions. These additional sessions were added to ensure that the repeated intracranial infusions did not affect responding irreversibly. Following the last self-administration session, the patency of the catheter was verified by infusing morphine $(15 \mathrm{mg} / \mathrm{kg})$ into the catheter in a volume of $1 \mathrm{ml} / \mathrm{kg}$ body weight. The catheter was considered patent if morphine produced rapid ataxia. Only those animals that were patent were included in the data analysis.

\section{Sucrose-Maintained Responding}

To assess the effect of ACe inactivation on sucrosemaintained responding, the pretraining procedures were similar to those described in the amphetamine selfadministration experiments, except that rats spent one session responding for sucrose on an FR-1 schedule, one session on an FR-2 schedule, and three sessions on an FR-5 schedule. They were then given ad libitum access to food to regain their free-feed body weight. Rats were maintained on ad libitum food access for the remainder of the experiment. One week after stereotaxic surgery to implant cannulae into the region of the $\mathrm{ACe}$, rats were then introduced to the operant-conditioning chamber for 15-min sessions in which five responses (FR-5) on one lever (active) were followed by delivery of a sucrose pellet (Noyes; $45 \mathrm{mg}$ ). Responses made on the other lever (inactive) were recorded but had no programmed consequence. In contrast to the $60-\mathrm{min}$ session used in the amphetamine self-administration experiment, the session length was only $15 \mathrm{~min}$ to avoid satiation across the session. After 15 sessions on the FR- 5 schedule, rats received intracranial infusions of muscimol and PBS across two sessions immediately before the session. Following the initial set of intracranial infusions, rats had an additional four sessions of responding for sucrose and then had an additional set of infusions of muscimol and PBS before the session.

\section{Histology}

Rats were administered an overdose of sodium pentobarbital $(150 \mathrm{mg} / \mathrm{kg}, \mathrm{IP})$. The brain was removed and $60 \mu \mathrm{m}$ frozen serial sections were taken and stained with thionin (Sigma). The sections were examined under a light microscope to determine cannulae placement. The most ventral point of each injection track was mapped onto the appropriate plate from the rat brain atlas of Paxinos and Watson (1998).

\section{Data Analysis}

To determine if a relationship existed between the two novelty tests, Pearson correlations were conducted. Data for each experiment were analyzed using an analysis of variance (ANOVA) procedure. Individual differences in the two novelty tests were analyzed as a between-subject factor (Group) in separate ANOVAs, with Treatment (Muscimol vs PBS) and Dose $(0.1,0.03,0.01,0.001 \mathrm{mg} / \mathrm{kg} /$ infusion and saline) as between-subjects factors and number of infusions or sucrose pellets earned as a within-subject factor. In addition, data from within the 60-min sessions were analyzed across 5-min blocks using a mixed-factorial
ANOVA. For all ANOVAs, the $\alpha$ level was set at 0.05 . Where appropriate, median split groups (HR vs LR; highnovelty seekers $v s$ low-novelty seekers) were compared within a given dose or session using Bonferroni corrected simple effects or planned comparisons $(p<0.01)$.

\section{RESULTS}

\section{Histology}

Figure 1 shows the injection cannula placement within the region of the ACe. A total of 30 rats out of 45 had accurate cannulae placement and patent catheters and only these 30 rats were included in the data analysis.

\section{Novelty Tests}

The range of scores (number of photobeam interruptions) for the inescapable novelty test was $243-679$, with a median score of 413. The range of scores (place preference ratio) for the novelty place preference test was $0.39-0.68$, with a median score of 0.58 . The correlation between these two tests was not significant (results not shown).

\section{Training of Amphetamine Self-Administration}

To determine whether the rate of responding during initial training of amphetamine $(0.1 \mathrm{mg} / \mathrm{kg} /$ infusion $)$ self-administration differed based on either of the two novelty tests, a mixed-factorial ANOVA was performed, using Group classification as the between-subjects factor. When activity in inescapable novelty was used as the between-subjects factor, ANOVA revealed a significant main effect of FR Value, $\mathrm{F}_{(3,84)}=31.96, \quad p<0.001, \quad$ Group, $\mathrm{F}_{(1,28)}=8.25$, $p<0.01$, and a significant interaction between FR Value and Group, $F_{(3,84)}=49.30, p<0.01$. Both HR and LR rats earned the most amphetamine infusions on the initial FR-1 schedule, likely due to both the low response requirement and pretraining with sucrose reinforcement. More important, HR rats self-administered significantly more amphetamine than LR rats during the FR-1, FR-2, and FR-3 training sessions. However, there was no significant difference between HR and LR rats during FR-5 training sessions, indicating that $\mathrm{HR}$ and LR rats responded at similar rates at the end of acquisition training (Figure 2a). When novelty place preference was used as the between-subjects factor, ANOVA revealed a significant main effect of FR Value, $\mathrm{F}_{(3,84)}=27.27, p<0.001$ and a significant interaction between FR Value and Group, $\mathrm{F}_{(3,84)}=4.51$, $p<0.01$. However, planned comparisons did not reveal any significant differences between high- and low-novelty seekers at any of the FR values used during training (Figure 2b).

\section{Individual Differences in Effect of ACe Inactivation on Amphetamine Self-Administration}

Based on activity in inescapable novelty, 14 rats were classified as HR and 16 rats were classified as LR. Following PBS intracranial infusions, HR rats self-administered more amphetamine than LR rats at unit doses of $0.03 \mathrm{mg} / \mathrm{kg} /$ infusion, $\mathrm{F}_{(1,112)}=4.42, p<0.05$, and $0.01 \mathrm{mg} / \mathrm{kg} /$ infusion, 

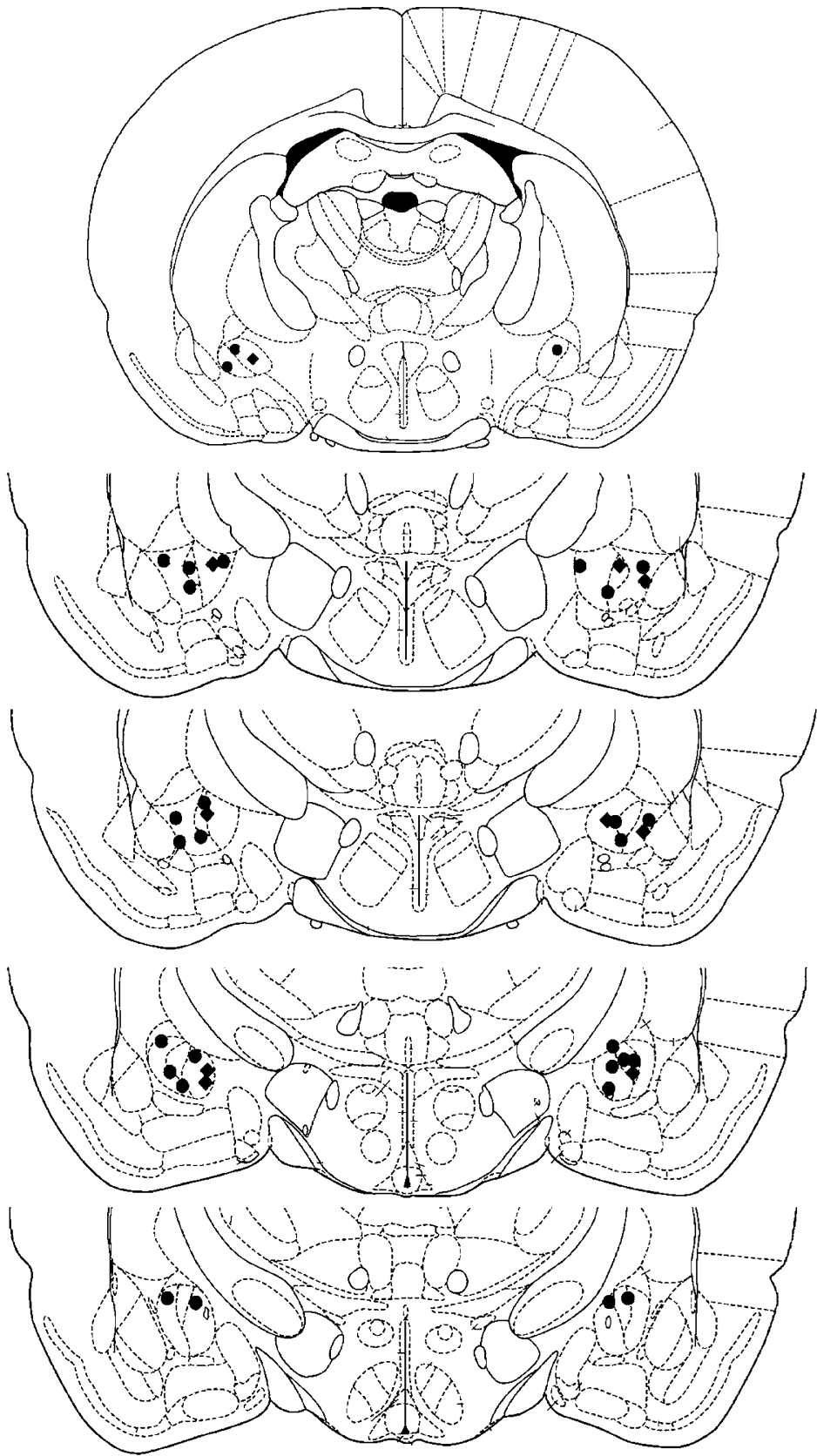

Figure I Microinfusion cannulae placements as verified by thionin-stained sections. Symbols

amphetamine self-administration;

sucrose-maintained responding) represent the most ventral point of the injector tract for each rat on coronal sections based on the atlas of Paxinos and Watson (I998). Numbers indicate the distance from Bregma in millimeters.

$\mathrm{F}_{(1,112)}=15.97, p<0.05$ (Figure 3). At these two unit doses of amphetamine, ACe inactivation with muscimol significantly attenuated amphetamine self-administration in HR rats, but not in LR rats (Figure 3). ANOVA on these data revealed a main effect of Treatment, $\mathrm{F}_{(1,28)}=45.28, p<0.001$, Dose $\mathrm{F}_{(4,112)}=28.64, p<0.001$, and significant interactions between Treatment and Group, $\mathrm{F}_{(1,28)}=6.34, p<0.05$, Treatment and Dose, $\mathrm{F}_{(4,112)}=4.28, p<0.01$, and Treatment, Dose, and Group $\mathrm{F}_{(4,112)}=4.60, p<0.01$. Subsequent tests revealed that inactivation of the ACe significantly decreased the number of infusions earned in HR at unit doses of rats at the $0.03 \mathrm{mg} / \mathrm{kg} /$ infusion, $\mathrm{F}_{(1,112)}=32.90, p<0.01$, and
$0.01 \mathrm{mg} / \mathrm{kg} /$ infusion, $\mathrm{F}_{(1,112)}=21.74, p<0.01$, whereas muscimol infusions did not significantly alter the number of infusions earned in LR rats at any of the unit doses tested.

Infusions of muscimol into the ACe had no effect on inactive lever responding in HR or LR rats (mean \pm SE across doses in HR: Muscimol $=2.29 \pm 0.67$ to $8.63 \pm 3.87$, $\mathrm{PBS}=4.93 \pm 3.71$ to $12.64 \pm 2.46$; LR: Muscimol $=2.19 \pm$ 0.62 to $15.25 \pm 3.62, \mathrm{PBS}=5.50 \pm 1.53$ to $19.38 \pm 5.48)$. An ANOVA on inactive lever responding revealed no significant main effect of Group $(\mathrm{F}<1)$ or any significant interactions with Group $(\mathrm{F}<1)$. While inactivation of the ACe did not differentially affect responding during the 


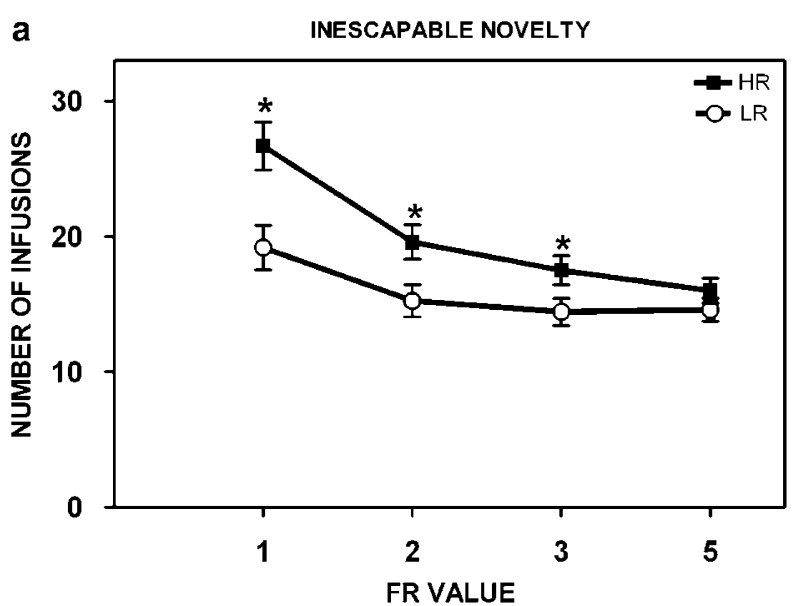

b

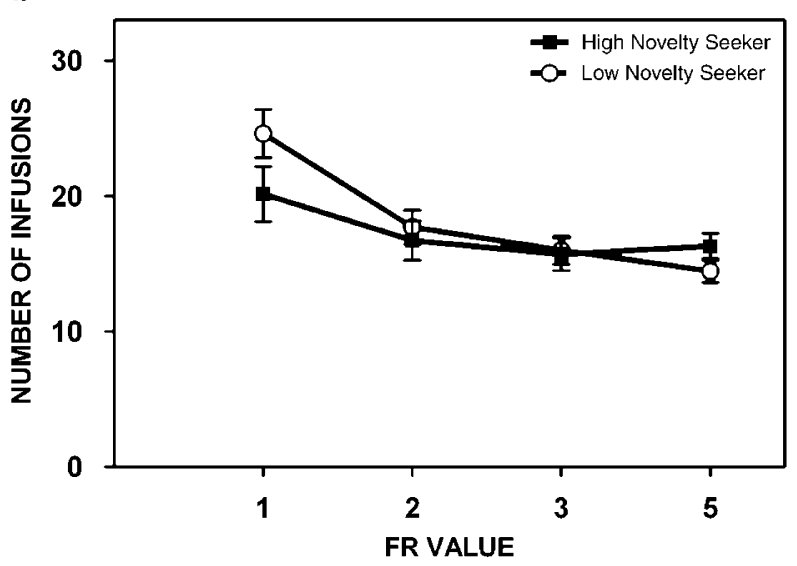

Figure 2 Acquisition of amphetamine self-administration $(0.1 \mathrm{mg} / \mathrm{kg} /$ infusion) in rats classified on inescapable novelty test as high responder $(H R)$ or low responder (LR) (a) and in rats classified on novelty place preference test as high novelty seekers or low novelty seekers (b). Data are expressed as mean + SEM number of amphetamine infusions for the sessions at each fixed ratio (FR) value. * Indicates a significant difference from $L R$ rats $(p<0.0 I)$.

time-out period in HR and LR rats $(\mathrm{F}<1)$, inactivation did significantly decrease responding during the time-out period at the $0.001 \mathrm{mg} / \mathrm{kg} /$ infusion dose, $\mathrm{F}_{(1,112)}=6.93$, $p<0.01$, regardless of group classification.

Based on novelty place preference, 13 rats were classified as high-novelty seekers and 17 rats were classified as lownovelty seekers. Following PBS intracranial infusions, highnovelty-seeking rats self-administered more amphetamine than low-novelty-seeking rats at a unit dose of $0.01 \mathrm{mg} / \mathrm{kg} /$ infusion, $\mathrm{F}_{(1,112)}=18.91, p<0.05$ (Figure 4). ACe inactivation decreased responding in both high- and low-noveltyseeking rats (Figure 4). ANOVA revealed a main effect of Treatment, $\mathrm{F}_{(1,28)}=34.62, p<0.001$, Dose, $\mathrm{F}_{(4,112)}=31.63$, $p<0.001$, Group, $\mathrm{F}_{(1,28)}=6.86, p<0.05$, and significant interactions between Dose and Group, $\mathrm{F}_{(4,112)}=3.04$, $p<0.05$, and Treatment and Dose, $\mathrm{F}_{(4,112)}=3.00, p<0.05$. ACe inactivation decreased the number of infusions earned in high-novelty-seeking rats at a unit dose of $0.01 \mathrm{mg} / \mathrm{kg} /$ infusion, $\mathrm{F}_{(1,112)}=12.94, p<0.01$. Conversely, inactivation significantly reduced the number of infusions earned in low-novelty-seeking rats at unit doses of $0.03 \mathrm{mg} / \mathrm{kg} /$ a HR

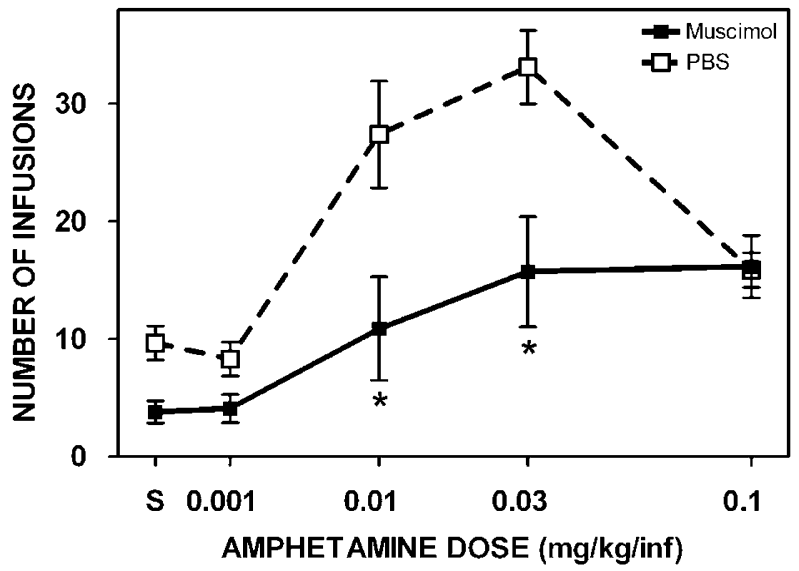

b

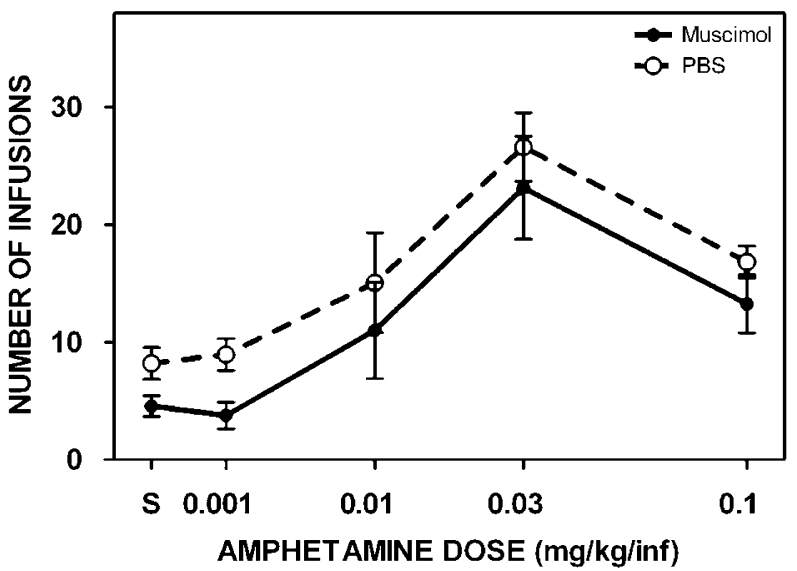

Figure 3 Effect of muscimol or phosphate-buffered saline (PBS) infusions on the number of amphetamine infusions earned in rats classified on inescapable novelty test as high responder (HR) (a) or low responder (LR) (b). Data are expressed as mean \pm SEM number of amphetamine infusions for each unit dose. *Indicates a significant difference from the PBS group $(p<0.01)$.

infusion, $\mathrm{F}_{(1,112)}=22.23, p<0.01$, and $0.01 \mathrm{mg} / \mathrm{kg} /$ infusion, $\mathrm{F}_{(1,112)}=11.96, p<0.01$.

Based on novelty-place preference, an ANOVA on inactive lever responding revealed significant main effects of Treatment, $\mathrm{F}_{(1,28)}=67.73, p<0.001$, Dose, $\mathrm{F}_{(4,112)}=23.77$, $p<0.001$, and Group, $\mathrm{F}_{(1,28)}=6.43, p<0.05$. Muscimol significantly reduced inactive lever responding in highnovelty-seeking rats at unit doses of $0.03 \mathrm{mg} / \mathrm{kg} / \mathrm{infusion}$, $\mathrm{F}_{(1,112)}=19.44, p<0.01$ (mean $\pm \mathrm{SE}$; high-novelty seekers: Muscimol $=10.46 \pm 2.24, \mathrm{PBS}=22.69 \pm 5.91$; low-novelty seekers: Muscimol $=6.82 \pm 1.96, \mathrm{PBS}=6.88 \pm 5.17)$ and $0.01 \mathrm{mg} /$ $\mathrm{kg}$ /infusion, $\mathrm{F}_{(1,112)}=7.99, p<0.01$ (mean \pm SE; high novelty seekers: Muscimol $=6.62 \pm 1.77, \mathrm{PBS}=14.46 \pm 9.41$; low-novelty seekers: Muscimol $=3.88 \pm 1.54, \mathrm{PBS}=9.41 \pm 2.15)$. An ANOVA on responding during the time-out period revealed significant main effects of Treatment, $\mathrm{F}_{(1,28)}=34.62$, $p<0.001$, Dose, $\mathrm{F}_{(4,112)}=31.63, p<0.001$, and Group, $\mathrm{F}_{(1,28)}=6.85, p<0.05$ and significant interactions between Dose and Group, $\mathrm{F}_{(4,112)}=3.04, p<0.05$, and Dose and Treatment, $\mathrm{F}_{(4,112)}=2.99, p<0.05$. Muscimol significantly reduced responding during the time-out period in low- 
a

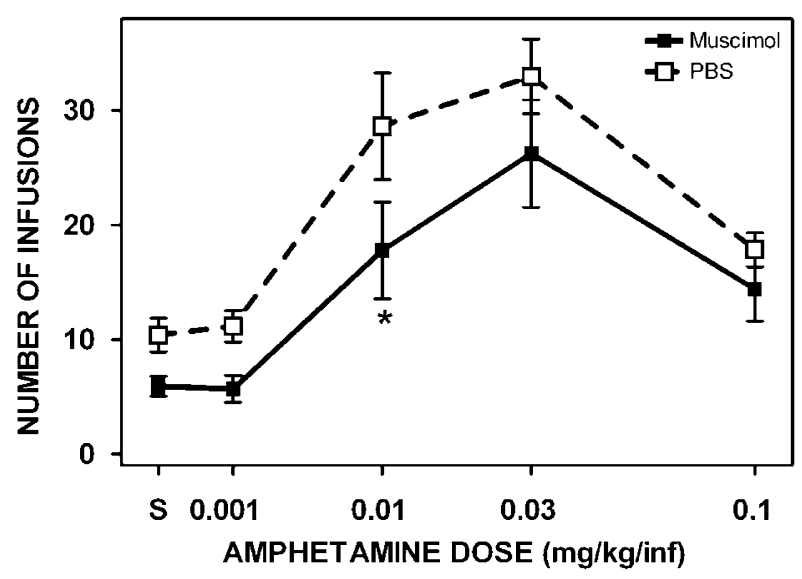

b

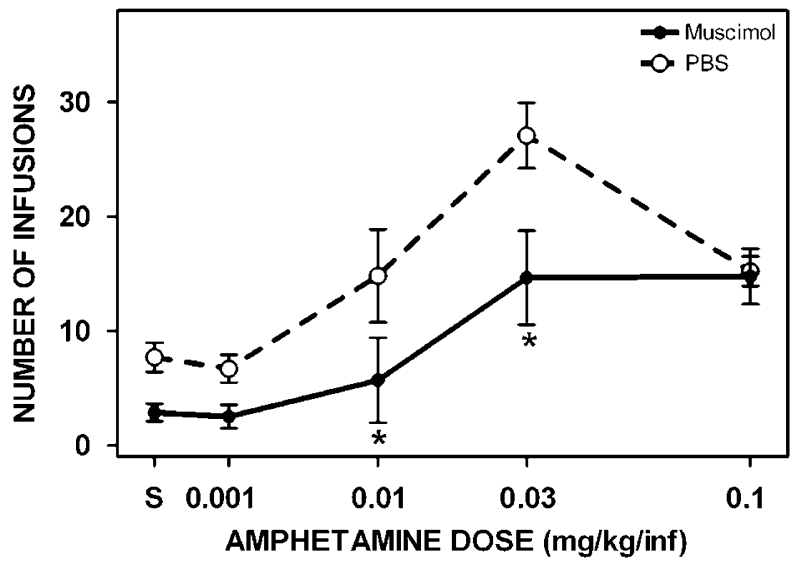

Figure 4 Effect of muscimol or phosphate-buffered saline (PBS) infusions on the number of amphetamine infusions earned in rats classified on novelty place preference test as high-novelty seekers (a) or low-novelty seekers (b). Data are expressed as mean \pm SEM number of amphetamine infusions for each unit dose. *Indicates a significant difference from the PBS group $(p<0.01)$.

novelty-seeking rats at unit doses of $0.03 \mathrm{mg} / \mathrm{kg} /$ infusion, $\mathrm{F}_{(1,112)}=7.54, p<0.01 \quad$ (mean $\pm \mathrm{SE}$; low-novelty seekers: Muscimol $=14.65 \pm 4.12, \quad \mathrm{PBS}=27.08 \pm 2.85)$ and $0.01 \mathrm{mg} /$ $\mathrm{kg}$ /infusion, $\mathrm{F}_{(1,112)}=24.09, p<0.01$ (mean $\pm \mathrm{SE}$; low-novelty seekers: Muscimol $=5.71 \pm 3.7, \mathrm{PBS}=14.82 \pm 4.06)$. At the $0.001 \mathrm{mg} / \mathrm{kg} /$ infusion and saline doses, inactivation decreased responding during the time-out period in both high- and low-novelty-seeking rats (results not shown).

In an effort to determine if the observed effects of inactivation were a result of order effects of our microinfusions, we conducted a multivariate ANOVA with order as the independent variable and number of infusions earned at each dose during each infusion as the set of dependent variables. The analysis showed no significant order effects on any of the dependent variables, Wilks' $\lambda=0.006$, $p=0.354$. In addition, following the last session at the saline dose, a subset of rats $(n=10)$ received an additional three sessions at the original training dose $(0.1 \mathrm{mg} / \mathrm{kg} /$ infusion) followed by an additional set of microinfusions. The number of infusions earned during the initial set of microinfusions was not significantly different from the

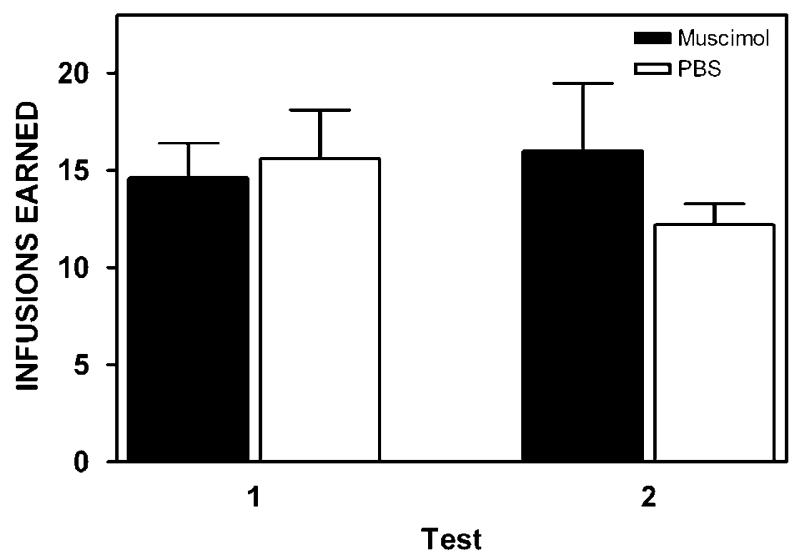

Figure 5 Mean \pm SEM number of amphetamine infusions $(0.1 \mathrm{mg} / \mathrm{kg} /$ infusion) earned following the initial set of microinfusions (Test I) and final set of microinfusions at the end of the experiment (Test 2). PBS, phosphate-buffered saline.

number of infusions earned during the second set of microinfusions at the original training dose (Figure 5). A 2 (Treatment) by 2 (Time) ANOVA did not reveal any significant main effects or interactions, indicating that the repeated microinjection procedure used across sessions produced no lasting alteration in ongoing amphetamine self-administration behavior.

\section{Onset of Inactivation Effects}

To determine the time course for ACe inactivation across the 60-min session, we examined the number of infusions earned during each 5-min block at a dose where inactivation had no effect $(0.1 \mathrm{mg} / \mathrm{kg} /$ infusion $)$ and at a dose where inactivation significantly reduced responding $(0.03 \mathrm{mg} / \mathrm{kg} /$ infusion). Based on activity in inescapable novelty, at the $0.1 \mathrm{mg} / \mathrm{kg} /$ infusion dose, there was a main effect of Block, $\mathrm{F}_{(11,308)}=31.74, \quad p<0.001$, with responding decreasing across the session regardless of Group classification; there were no significant effects of inactivation in HR or LR rats during the session (Figure 6a and b). At the $0.03 \mathrm{mg} / \mathrm{kg} /$ infusion dose, there were main effects of Treatment, $\mathrm{F}_{(1,28)}=9.79, p<0.01$, and Block, $\mathrm{F}_{(11,308)}=5.53, p<0.001$. Inactivation significantly reduced responding for $\mathrm{HR}$ rats (Figure 6c) during Blocks 1-7 and 11-12, $\mathrm{F}_{(1,308)}>6.73$, $p<0.01$. However, in LR rats (Figure 6d), inactivation only reduced responding during Block $9, \mathrm{~F}_{(1,308)}=7.46, p<0.01$.

Based on novelty place preference, at the $0.1 \mathrm{mg} / \mathrm{kg} /$ infusion dose, there was a main effect of Block, $\mathrm{F}_{(11,308)}=$ $33.80, p<0.001$, with responding decreasing across the session regardless of group classification. There were no significant effects of inactivation in high- and low-noveltyseeking rats during the session. At the $0.03 \mathrm{mg} / \mathrm{kg} /$ infusion dose, there were main effects of Treatment, $\mathrm{F}_{(1,28)}=15.88$, $p<0.001$, Block, $\mathrm{F}_{(11,308)}=3.28, p<0.001$, and Group, $\mathrm{F}_{(1,28)}=6.40, p<0.05$. Inactivation significantly reduced responding in high-novelty-seeking rats during Blocks 1,6 , and $9, \mathrm{~F}_{(1,108)}>7.03, p<0.01$, while inactivation significantly reduced responding in low-novelty-seeking rats during Blocks 2-5, and 10-11, $\mathrm{F}_{(1,108)}>6.94, p<0.01$ (results not shown). 

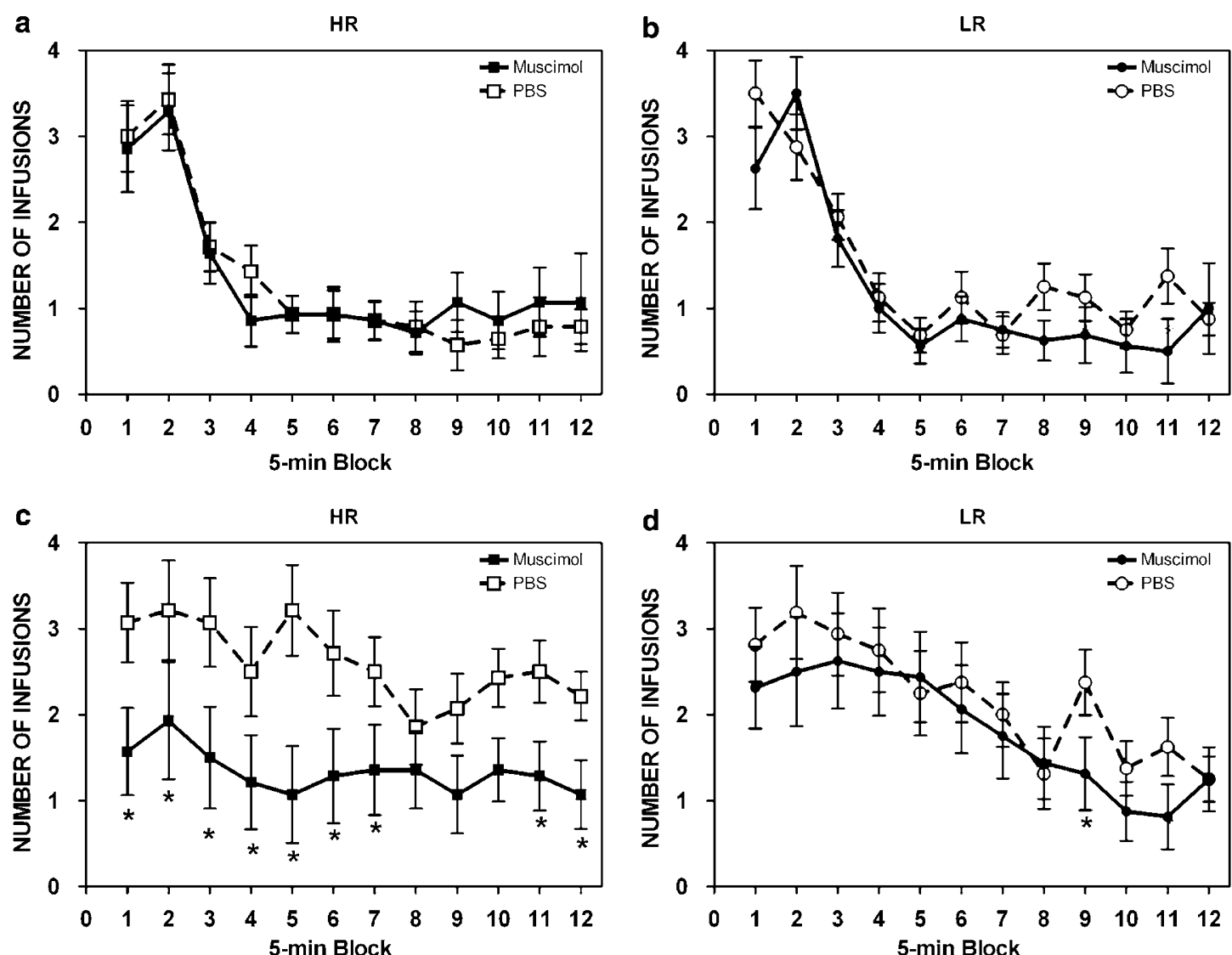

Figure 6 Time course effect of muscimol or phosphate-buffered saline (PBS) infusions on responding for amphetamine in rats classified on inescapable novelty test as high responder (HR) or low responder (LR). Data are expressed as mean \pm SEM number of amphetamine infusions across 5 -min blocks for the 0.1 ( $a$ and b) and 0.03 ( $c$ and d) $\mathrm{mg} / \mathrm{kg}$ /infusion unit doses in HR rats (a, c) or LR rats (b, d). * Indicates a significant difference from the PBS group $(p<0.01)$.

\section{Individual Differences in Effects of ACe Inactivation on Sucrose-Maintained Responding}

For this experiment, a total of ten rats (five HR and five LR) had correct cannula placement in the region of the ACe (Figure 1). Based on activity in inescapable novelty, HR and LR rats did not differ in the acquisition of sucrosereinforced responding. During the first five acquisition sessions, there was a main effect of $F R$ value, $F_{(2,18)}=30.14$, $p<0.001$, due to an increase in responding as the FR value increased, but there was no significant main effect or interaction with Group. HR and LR rats did not differ in the number of sucrose pellets earned during the three sessions before the first (mean $\pm \mathrm{SE}$; HR $=29 \pm 7.3, \mathrm{LR}=38.3 \pm 5.9$ ) or second (mean $\pm \mathrm{SE} ; \mathrm{HR}=33.4 \pm 5.1, \mathrm{LR}=29.3 \pm 1$ ) set of microinfusions. Regardless of group classification, inactivation of the ACe significantly attenuated responding for sucrose as revealed by a main effect of Treatment, $\mathrm{F}_{(1,8)}=12.76, p<0.01 \quad($ mean $\pm \mathrm{SE}$; Muscimol $=12.3 \pm 2.23$, $\mathrm{PBS}=20.25 \pm 2.72$ ); however, there were no main effects or interactions with Group. There were also no differential effects of inactivation between the first and second set of microinfusions, and therefore, the mean of both infusions was used to calculate simple effects. Subsequent simple effects revealed no significant difference in $\mathrm{HR}, \mathrm{F}_{(1,4)}=6.11$, $p>0.05($ mean \pm SE; Muscimol $=11.7 \pm 3.4, \mathrm{PBS}=22.7 \pm 3.8)$ or LR, $\mathrm{F}_{(1,4)}=1.21, \quad p>0.05 \quad($ mean $\pm \mathrm{SE} ; \quad$ Muscimol $=$ $12.9 \pm 3.3, \mathrm{PBS}=17.8 \pm 4)$ rats. HR and LR rats did not differ in the number of inactive lever presses and inactivation had no significant effect on the number of inactive lever presses (results not shown).

Based on the novelty place preference, six rats were classified as high-novelty seekers and four rats were classified as low-novelty seekers. While inactivation of the ACe attenuated responding for sucrose, $F_{(1,8)}=9.61$, $p<0.05$, there were no main effects or interactions with Group. High- and low-novelty seekers did not differ in the number of inactive lever presses and inactivation had no significant effect on the number of inactive lever presses (results not shown).

\section{Control Microinjection Sites}

A total of eight rats (four HR and four LR) served as infusion controls with correct cannula placements in cortical layers 2 and 3. ANOVA performed on the number of infusions of amphetamine earned at each dose revealed only a main effect of amphetamine dose, $\mathrm{F}_{(4,24)}=12.01$, $p<0.001$. There were no main effects of Treatment or Group, indicating that the effects of inactivation of the ACe were regionally specific. In a further effort to determine anatomical specificity, we conducted a mixed factorial 
ANOVA on the data from seven rats that were not included in the above analyses due to inaccurate cannulae placements. One or both injector tips were verified to be outside the targeted ACe, which included placements in the posterior basolateral nucleus, caudate putamen, and the shell of the nucleus accumbens. The ANOVA only revealed a main effect of Dose, $\mathrm{F}_{(4,20)}=7.94, p<0.01$, with no main effect of Treatment, indicating further that the effects of inactivation were regionally specific.

\section{DISCUSSION}

This study examined the hypothesis that the ACe contributes to the elevated rate of self-administration in HR rats compared to LR rats. HR rats self-administered more amphetamine than LR rats at unit doses of 0.03 and $0.01 \mathrm{mg} / \mathrm{kg} /$ infusion, a finding that is generally consistent with previous reports (Piazza et al, 1989; Pierre and Vezina, 1997; Klebaur et al, 2001). Inactivation of the ACe with muscimol attenuated self-administration in $\mathrm{HR}$ rats at these two doses only. In contrast, inactivation of the ACe had no effect on amphetamine self-administration at any dose in LR rats. Interestingly, inactivation of the ACe only decreased responding at the doses where $H R$ and $L R$ rats differed in rates of amphetamine self-administration following PBS infusions. Taken together, these results suggest that the projection neurons of the ACe contribute the increased self-administration of amphetamine by $\mathrm{HR}$ rats.

As with most intracranial microinjection studies, the involvement of brain sites outside the point of injection needs to be considered, as muscimol may have spread to areas adjacent to the ACe. Previous research suggests that a $1.0 \mu \mathrm{g} / 1.0 \mu \mathrm{l}$ infusion of muscimol diffuses in a sphere of at least $1.0 \mathrm{~mm}$ around the site of injection (Martin, 1991), and more recent research suggests that the spread may be greater (Edeline et al, 2002). In an attempt to minimize the spread of muscimol to other regions, in particular the basolateral complex (BLA), the cannula placements were targeted anterior and dorsomedial to the BLA. Based on previous work using neurotoxin injections, it is known that drug spread into the BLA from the ACe is inhibited due to fiber encapsulation of the ACe on its lateral and ventral borders (Kapp et al, 1993). While it is possible that some of the observed effects were due to diffusion of muscimol to neighboring amygdaloid nuclei, the lack of effect observed with our anatomical control infusions demonstrates that the attenuation of self-administration shows some regional specificity.

In addition to decreasing amphetamine self-administration in HR rats, ACe inactivation also decreased sucrosemaintained responding in both $H R$ and LR rats. This latter finding raises the possibility that the observed effects of ACe inactivation were due to a nonspecific response suppressant effect of muscimol. Although this possibility cannot be ruled out completely, it is unlikely because muscimol infusions had no effect on responding for low or high doses of amphetamine ( 0.001 or $0.1 \mathrm{mg} / \mathrm{kg} / \mathrm{infusion})$ and no reliable effect on inactive lever responding for either amphetamine or sucrose. In addition, it is difficult to envision why a nonspecific response suppressant effect would be obtained for self-administration in HR, but not LR rats.

It may also be important to consider the possibility that the differential effect of inactivation between HR and LR rats may reflect a rate dependency phenomenon. Previous work has shown that high rates of ongoing behavior decrease more than low rates of behavior when animals are given amphetamine (Dews and Wenger, 1977). Since HR rats had a higher baseline rate of responding than LR rats following PBS infusions at the 0.03 and $0.01 \mathrm{mg} / \mathrm{kg} /$ infusion doses, it may be that muscimol, similar to amphetamine, was more disruptive in HR rats due to the higher response rate. Contrary to this interpretation, however, the time course results showed that high response rates were obtained in both HR and LR rats early in the session using a unit dose of $0.1 \mathrm{mg} / \mathrm{kg} /$ infusion, but responding was not reliably decreased by muscimol infusions. In addition, based on novelty place preference, an amphetamine dose of $0.03 \mathrm{mg} / \mathrm{kg} /$ infusion produced similar response rates in both high- and low-novelty seekers, but muscimol decreased responding only in low-novelty seekers. Taken together, these observations suggest that it is unlikely that the differential effect of inactivation between HR and LR rats may be explained solely by a rate-dependency interpretation.

Consistent with previous research, HR and LR rats at their free-feed body weight did not differ in responding for sucrose (Klebaur et al, 2001; Cain et al, 2006). Moreover, while ACe inactivation decreased responding for sucrose, in contrast to amphetamine self-administration, it did not differentially affect HR and LR rats. This provides further evidence that the differential effects of ACe inactivation observed during self-administration are due to a role of the ACe in regulating the differential sensitivity to amphetamine in $\mathrm{HR}$ and LR rats. Regarding the ability of ACe inactivation to disrupt responding for sucrose, there are several possible interpretations. Previous research has demonstrated that the lesions of the ACe do not disrupt the acquisition of instrumental responding (Cador et al, 1989; Killcross et al, 1997; Burns et al, 1999; Hall et al, 2001). However, lesions of the ACe have been shown to disrupt Pavlovian-to-instrumental transfer (Hall et al, 2001), appetitive Pavlovian conditioning (Hall et al, 2001), and conditioned approach to an appetitive stimulus (Hitchcott and Phillips, 1998). Consistent with these observations, c-fos is activated within the ACe during appetitive conditioning, which further suggests a role of the ACe in appetitive learning (Knapska et al, 2006). Therefore, the observed effects of ACe inactivation on operant responding for sucrose suggest a role of the ACe in appetitive conditioning. As the ACe has been shown to be important for the coding of positive reward information (Kesner et al, 1989), the effects of ACe inactivation on responding for both sucrose and amphetamine may provide additional evidence that the ACe contributes to responding for positive rewards.

While it has been established that DA neurons within the ACe contribute to psychostimulant self-administration (Caine et al, 1995; Alleweireldt et al, 2006), little research has examined the role of the non-DA efferent projection ACe neurons in psychostimulant self-administration. In particular, a substantial number of intrinsic GABAergic 
neurons located within the ACe are known to innervate multiple brainstem projection neurons (Smith and Pare, 1994; Cassell et al, 1999). In the rat amygdala slice preparation, stimulation of the lateral subdivision of the ACe also elicits GABAergic inhibition of neurons in the medial subdivision (Nose et al, 1991), an area from which numerous efferent brainstem projections originate (Gray and Magnuson, 1987). In contrast to the finding that infusion of the DA $\mathrm{D}_{1}$ antagonist $\mathrm{SCH}-23390$ into the ACe increases cocaine self-administration (Caine et al, 1995; Alleweireldt et al, 2006), the current study demonstrates that infusion of muscimol decreases amphetamine selfadministration, at least in HR rats. DA terminals innervate GABA neurons in all divisions of the ACe (Asan, 1997), and recent evidence suggests that $\mathrm{DA}$ gates the signal flow through the amygdala via intercalated GABAergic neurons (Marowsky et al, 2005). While the use of muscimol does not differentiate between DA and non-DA neurons, the contrasting results obtained with SCH-23390 and muscimol suggests that the effects of muscimol obtained in the current report involves, at least in part, inactivation of non-DA neurons in the ACe.

The ability of ACe inactivation to decrease amphetamine self-administration in HR rats may be due to the predominately GABAergic projections to both the HPA axis and the ventral tegmental area (VTA) (Smith and Pare, 1994; Sun et al, 1994; Jongen-Relo and Amaral, 1998; Cassell et al, 1999). The observation that glucocorticoids can modulate DA transmission (Piazza et al, 1993); the suggestion that HR rats have a deregulation of their HPA axis (Piazza and Le Moal, 1997; Kabbaj, 2006); and the relationship between GABA and DA within in the ACe (Marowsky et al, 2005) suggest that the differences in dopaminergic sensitivity between HR and LR rats (Marinelli and White, 2000; Chefer et $a l, 2003)$ are due to differences in ACe regulation of the HPA axis, and that inactivation of the ACe in HR rats may result in a change in HPA axis activation.

Regardless of the specific neurotransmitters involved, projection neurons from the ACe to the HPA axis are likely to contribute to the differential sensitivity to amphetamine between $\mathrm{HR}$ and $\mathrm{LR}$ rats. Interestingly, when rats were classified based on novelty place preference, inactivation of the ACe differentially affected high- and low-noveltyseeking rats only at the $0.03 \mathrm{mg} / \mathrm{kg} /$ infusion unit dose of amphetamine, with inactivation decreasing responding for low-novelty-seeking rats only. Consistent with previous research, the novelty place preference test in the current study did not predict differences in amphetamine selfadministration (Klebaur et al, 2001; Cain et al, 2004). Given that ACe inactivation did not differentially affect high- and low-novelty-seeking rats, these results suggest that the effects of ACe inactivation are specific to the inescapable novelty test. Importantly, the tests for inescapable and freechoice novelty are not related to one another, and thus, they measure different aspects of response to novelty. While HR rats have a longer duration of corticosterone secretion after exposure to a novel environment (Piazza et al, 1991a), the novelty place preference test does not elevate levels of corticosterone (Misslin et al, 1982). This suggests that the ability of ACe inactivation to decrease responding for amphetamine in $\mathrm{HR}$ rats is due to a role of the ACe in activating the HPA axis (Beaulieu et al, 1986).
When animals are exposed to a stressor (Goeders and Guerin, 1994; Miczek and Mutschler, 1996; Piazza and Le Moal, 1998) or given repeated injections of corticosterone (Goeders and Guerin, 1996; Deroche et al, 1997; Mantsch et al, 1998), psychostimulant self-administration increases. Since glucocorticoids can modulate DA transmission (Piazza et al, 1993), it has been suggested that stress hormones may increase drug self-administration by facilitating DA transmission (Marinelli and Piazza, 2002). As mentioned previously, HR rats have a longer duration of corticosterone secretion than LR rats following exposure to a novel environment (Piazza et al, 1991a). In addition, HR rats are more sensitive to corticosterone (Piazza et al, 1993), and they have lower levels of glucocorticoid receptors in the hippocampus (Kabbaj et al, 2000). However, HR rats show less anxiety-like behaviors in the light-dark test, the elevated plus maze, and the open field test than LR rats (Dellu et al, 1996; Kabbaj et al, 2000; Stead et al, 2006). Further, social defeat stress increases cocaine self-administration in LR rats, but delays cocaine self-administration in HR rats (Kabbaj et al, 2001). One explanation for these seemingly conflicting results is that the increased vulnerability to drug abuse in HR rats is due to a deregulation of the HPA axis that results in hyperactivity of the mesolimbic dopamine system (Piazza and Le Moal, 1997; Kabbaj, 2006) and that perhaps the stress response itself is rewarding to HR rats (Piazza and Le Moal, 1997).

Interestingly, microinjections of muscimol into the $\mathrm{ACe}$ have been shown to result in an 'anxiolytic-like' response in the social interaction and elevated plus maze tests (Sanders and Shekhar, 1995; Moreira et al, 2007). Thus, it is possible that the muscimol microinfusions had an 'anxiolytic-like' effect and this decreased amphetamine self-administration in HR rats. While a direct measure of anxiety would be needed to address the issue fully, this explanation for the current results is not likely because the induction of anxiety via social defeat stress increases cocaine self-administration in LR rats and delays self-administration in HR rats (Kabbaj et al, 2001). Another possible explanation for the current results is that inactivation of ACe resulted in hyperactivity that competed with lever press responding. GABA inactivation of the ACe has no effect on locomotor activity observed over a $2 \mathrm{~h}$ period (McFarland et al, 2004). While this study did not directly evaluate locomotor activity, since responding was not decreased by muscimol uniformly across all of the unit doses of amphetamine, it seems unlikely that the dose-dependent effects obtained in HR rats simply reflects a nonspecific increase in locomotor activity.

In terms of translating this work to humans, it should be noted that the ability of the response to inescapable novelty to predict individual differences in drug use vulnerability is well established (Marinelli, 2005; Kabbaj, 2006). However, it is still uncertain if the response to inescapable novelty is a valid animal model of sensation seeking. In an attempt to determine the validity of this model, we recently examined the ability of inescapable and free-choice novelty tests to predict amphetamine self-administration using a large sample of rats. When novelty seeking was treated as a continuous variable to better model the research using human participants, the response to free-choice novelty was a better predictor of amphetamine self-administration than the response to inescapable novelty (Cain et al, 2005). While 
it remains unclear if the response to inescapable novelty adequately models sensation seeking, it is clear that this model predicts drug-use vulnerability (Marinelli, 2005; Kabbaj, 2006). The current findings suggest that the ACe may contribute to individual vulnerability to drug abuse, perhaps due to its role in regulating the stress response. These findings suggest that prevention and treatment interventions aimed at reducing stress may be useful strategies for decreasing drug-abuse vulnerability.

\section{ACKNOWLEDGEMENTS}

This research was funded by USPHS grant P50 DA05312. MEC supported by USPHS Grant F32 DA16013. We thank Justin Dixon, Bill Dotson, Laura Fenton, Nate Gilbertson, and Nichole Neugebauer for their assistance with this project.

\section{DISCLOSURE/CONFLICT OF INTERESTS}

The authors declare that this work was funded by NIH grants DA05312 and DA16013. We declare that, except for the income received from our primary employers, no financial support or compensation has been received from any individual or corporate entity over the past 3 years for research or professional service and there are no personal financial holdings that could be perceived as constituting a potential conflict of interests.

\section{REFERENCES}

Alheid GF, Heimer L (1988). New perspectives in basal forebrain organization of special relevance for neuropsychiatric disorders: the striatopallidal, amygdaloid, and corticopetal components of the substantia innominata. Neuroscience 27: 1-39.

Alleweireldt AT, Hobbs RJ, Taylor AR, Neisewander JL (2006). Effects of SCH-23390 infused into the amygdala or adjacent cortex and basal ganglia on cocaine seeking and self-administration in rats. Neuropsychopharmacology 31: 363-374.

Asan E (1997). Interrelationships between tyrosine hydroxylaseimmunoreactive dopaminergic afferents and somatostatinergic neurons in the rat central amygdaloid nucleus. Histochem Cell Biol 107: 65-79.

Bardo MT, Donohew RL, Harrington NG (1996). Psychobiology of novelty seeking and drug seeking behavior. Behav Brain Res 77: 23-43.

Beaulieu S, DiPaolo T, Barden N (1986). Control of ACTH secretion by the central nucleus of the amygdala: implication of the serotonergic system and its relevance to the glucocorticoid delayed feedback mechanism. Neuroendocrinology 44: 247-254.

Bevins RA, Klebaur JE, Bardo MT (1997). Individual differences in response to novelty, amphetamine-induced activity and drug discrimination in rats. Behav Pharmacol 8: 113-123.

Bradberry CW, Gruen RJ, Berridge CW, Roth RH (1991). Individual differences in behavioral measures: correlations with nucleus accumbens dopamine measured by microdialysis. Pharmacol Biochem Behav 39: 877-882.

Burns LH, Everitt BJ, Robbins TW (1999). Effects of excitotoxic lesions of the basolateral amygdala on conditional discrimination learning with primary and conditioned reinforcement. Behav Brain Res 100: 123-133.

Cador M, Dulluc J, Mormede P (1993). Modulation of the locomotor response to amphetamine by corticosterone. Neuroscience 56: 981-988.
Cador M, Robbins TW, Everitt BJ (1989). Involvement of the amygdala in stimulus-reward associations: interaction with the ventral striatum. Neuroscience 30: 77-86.

Cain ME, Dotson WF, Bardo MT (2006). Individual differences in the effect of novel environmental stimuli prior to amphetamine self-administration in rats. Exp Clin Psychopharmacol 114: 389-401.

Cain ME, Saucier DA, Bardo MT (2005). Novelty seeking and drug use: contribution of an animal model. Exp Clin Psychopharmacol 13: $367-375$.

Cain ME, Smith CM, Bardo MT (2004). The effect of novelty on amphetamine self-administration in rats classified as high and low responders. Psychopharmacology 176: 129-138.

Caine SB, Heinrichs SC, Coffin VL, Koob GF (1995). Effects of the dopamine D-1 antagonist SCH 23390 microinjected into the accumbens, amygdala, or striatum on cocaine self-administration in the rat. Brain Res 692: 47-56.

Cassell MD, Freedman LJ, Shi C (1999). The intrinsic organization of the central extended amygdala. In: McGinty JF (ed). Advancing from the Ventral Striatum to the Extended Amygdala: Implications for Neuropsychiatry and Drug Abuse. The New York Academy of Sciences: New York. pp 217-241.

Chefer VI, Zakharova I, Shippenberg TS (2003). Enhanced responsiveness to novelty and cocaine is associated with decreased basal dopamine uptake and release in the nucleus accumbens: quantitative microdialysis in rats under transient conditions. J Neurosci 23: 3076-3084.

Chevrette J, Stellar JR, Hesse GW, Markou A (2002). Both the shell of the nucleus accumbens and the central nucleus of the amygdala support amphetamine self-administration. Pharmacol Biochem Behav 71: 501-507.

Davis M, Whalen PJ (2001). The amygdala: vigilance and emotion. Mol Psychiatry 6: 13-34.

Dellu F, Mayo W, Vallee M, Maccari S, Piazza PV, Le Moal M et al (1996). Behavioral reactivity to novelty during youth as a predictive factor of stress-induced corticosterone secretion in the elderly - a life-span study in rats. Psychoneuroendocrinology 21: 441-453.

Deroche V, Marinelli M, Le Moal M, Piazza PV (1997). Glucocorticoids and behavioral effects of psychostimulants. II: cocaine intravenous self-administration and reinstatement depend on glucocorticoid levels. J Pharmacol Exp Ther 281: 1401-1407.

Dews PB, Wenger GR (1977). Rate-dependency of the behavioral effects of amphetamine. In: Thompson T, Dews PB (eds). Advances in Behavioral Pharmacology. Academic Press: New York. pp 167-212.

Donohew RL, Lorch EP, Palmgreen P (1991). Sensation seeking and targeting of televised anti-drug PSAs. In: Donohew L, Sypher H, Bukowski WJ (eds). Persuasive Communication and Drug Abuse Prevention. Lawrence Erlbaum: Hillsdale. pp 209-226.

Edeline JM, Hars B, Hennevin E, Cotillon N (2002). Muscimol diffusion after intracerebral microinjections: a reevaluation based on electrophysiological and autoradiographic quantifications. Neurobiol Learn Mem 78: 100-124.

Epping-Jordan MP, Markou A, Koob GF (1998). The dopamine D-1 receptor antagonist SCH 23390 injected into the dorsolateral bed nucleus of the stria terminalis decreased cocaine reinforcement in the rat. Brain Res 784: 105-115.

Exner M, Clark D (1993). Behaviour in the novel environment predicts responsiveness to d-amphetamine in the rat: a multivariate approach. Behav Pharmacol 4: 47-56.

Gingras MA, Cools AR (1997). No major differences in locomotor responses to dexamphetamine in high and low responders to novelty: a study of Wistar rats. Pharmacol Biochem Behav 57: 857-862. 
Goeders NE, Guerin GF (1994). Non-contingent electric footshock facilitates the acquisition of intravenous cocaine self-administration in rats. Psychopharmacology 114: 63-70.

Goeders NE, Guerin GF (1996). Role of corticosterone in intravenous cocaine self-administration in rats. Neuroendocrinology 64: 337-348.

Gray TS, Magnuson DJ (1987). Neuropeptide neuronal efferents from the bed nucleus of the stria terminalis and central amygdaloid nucleus to the vagal dorsal complex in the rat. J Comp Neurol 262: 365-374.

Hall J, Parkinson JA, Connor TM, Dickinson A, Everitt BJ (2001). Involvement of the central nucleus of the amygdala and nucleus accumbens core in mediating Pavlovian influences on instrumental behaviour. Eur J Neurosci 13: 1984-1992.

Heimer L, deOlmos J, Alheid GF, Zaborsky L (1991). 'Perestroika' in the basal forebrain: opening the border between neurology and psychiatry. In: Holstege G (ed). Progress in Brain Research. Elsevier: Amsterdam. pp 109-165.

Hitchcott PK, Phillips GD (1998). Double dissociation of the behavioral effects of $\mathrm{R}(+)$ 7-OH-DPAT infusions in the central and basolateral amygdala nuclei upon Pavlovian and instrumental conditioned appetitive behaviors. Psychopharmacology 140: $458-469$.

Hooks MS, Jones GH, Smith AD, Neill DB, Justice JB (1991). Individual differences in locomotor activity and sensitization. Pharmacol Biochem Behav 38: 467-470.

Jongen-Relo AL, Amaral DG (1998). Evidence for a GABAergic projection from the central nucleus of the amygdala to the brainstem of the macaque monkey: a combined retrograde tracing and in situ hybridization study. Eur J Neurosci 10: 2924-2933.

Kabbaj M (2006). Individual differences in vulnerability to drug abuse: the high responders/low responders model. CNS Neurol Disord Drug Targets 5: 513-520.

Kabbaj M, Devine DP, Savage VR, Akil H (2000). Neurobiological correlates of individual differences in novelty seeking behavior in the rat: differential expression of stress-related molecules. J Neurosci 20: 6893-6988.

Kabbaj M, Norton CS, Kollack-Walker S, Watson SJ, Robinson TE, Akil H (2001). Social defeat alters acquisition of cocaine selfadministration in rats: role of individual differences in cocainetaking behavior. Psychopharmacology 158: 382-387.

Kapp B, Silverstri A, Guaracci F, Moynihan JE, Cain ME (1997). Associative and EEG arousal-related characteristics of amygdaloid central nucleus neurons in the rabbit. Soc Neurosci Abstr 23: 787.

Kapp BS, Cain ME (2001). The neural basis of arousal. In: Smelser NJ, Battes PB (eds). International Encyclopedia of the Social and Behavioral Sciences. Elsevier Science: New York. pp 754-758.

Kapp BS, Whalen PJ, Silvestri AJ, Jordan MP, Fechter JH (1993). The effect of amygdaloid lesions on the acquisition of EEG and heart rate conditioned responses in the rabbit. Soc Neurosci Abstr 19: 1230.

Kesner RP, Walser RD, Winzenried G (1989). Central but not basolateral amygdala mediates memory for positive affective experiences. Behav Brain Res 33: 189-195.

Killcross S, Robbins TW, Everitt BJ (1997). Different types of fear-conditioned behaviour mediated by separate nuclei within amygdala. Nature 388: 377-380.

Klebaur JE, Bardo MT (1999). Individual differences in novelty seeking on the playground maze predict amphetamine conditioned place preference. Pharmacol Biochem Behav 63: 131-136.

Klebaur JE, Bevins RA, Segar TM, Bardo MT (2001). Individual differences in behavioral responses to novelty and amphetamine self-administration in male and female rats. Behav Pharmacol 12: 267-275.

Knapska E, Walasek G, Nikolaev E, Neuhausser-Wespy F, Lipp HP, Kaczmarek L et al (2006). Differential involvement of the central amygdala in appetitive versus aversive learning. Learn Mem 13: 192-200.

Kruzich PJ, See RE (2001). Differential contributions of the basolateral and central amygdala in the acquisition and expression of conditioned relapse to cocaine-seeking behavior. J Neurosci 21: RC155.

Li CS, Mazzoni P, Andersen RA (1999). Effect of reversible inactivation of macaque lateral intraparietal area on visual and memory saccades. J Neurophysiol 81: 1827-1838.

Manning BH (1998). A lateralized deficit in morphine antinociception after unilateral inactivation of the central amygdala. J Neurosci 18: 9453-9470.

Mantsch JR, Saphier D, Goeders NE (1998). Corticosterone facilitates the acquisition of cocaine self-administration in rats: opposite effects of the type II glucocorticoid receptor agonist dexamethasone. J Pharmacol Exp Ther 287: 72-80.

Marinelli M (2005). The many aspects of the locomotor response to a novel environment test: theoretical comment on Mitchell, Cunningham, and Mark (2005). Behav Neurosci 119: 1144-1151.

Marinelli M, Piazza PV (2002). Interaction between glucocorticoid hormones, stress and psychostimulant drugs. Eur J Neurosci 16: 387-394.

Marinelli M, White FJ (2000). Enhanced vulnerability to cocaine self-administration is associated with elevated impulse activity of midbrain dopamine neurons. J Neurosci 20: 8876-8885.

Marowsky A, Yanagawa Y, Obata K, Vogt KE (2005). A specialized subclass of interneurons mediates dopaminergic facilitation of amygdala function. Neuron 48: 1025-1037.

Martin JH (1991). Autoradiographic estimation of the extent of reversible inactivation produced by microinjection of lidocaine and muscimol in the rat. Neurosci Lett 127: 160-164.

Martinez RC, de Oliveira AR, Brandao ML (2006). Conditioned and unconditioned fear organized in the periaqueductal gray are differentially sensitive to injections of muscimol into amygdaloid nuclei. Neurobiol Learn Mem 85: 58-65.

McEchron MD, McCabe PM, Green EJ, Llabre MM, Schneidermann NM (1995). Simultaneous single unit recordings in the medial geniculate nucleus and amygdaloid central nucleus through habituation, acquisition, and extinction of rabbits classically conditioned heart rate. Brain Res 682: 157-166.

McFarland K, Davidge SB, Lapish CC, Kalivas PW (2004). Limbic and motor circuitry underlying footshock-induced reinstatement of cocaine-seeking behavior. J Neurosci 24: 1551-1560.

Miczek KA, Mutschler NH (1996). Activational effects of social stress on IV cocaine self-administration in rats. Psychopharmacology 128: 256-264.

Misslin R, Herzog F, Koch B, Ropartz P (1982). Effects of isolation, handling, and novelty on the pituitary-adrenal response in the mouse. Psychoneuroendocrinology 7: 217-221.

Moreira CM, Masson S, Carvalho MC, Brandao ML (2007). Exploratory behaviour of rats in the elevated plus-maze is differentially sensitive to inactivation of the basolateral and central amygdaloid nuclei. Brain Res Bull 71: 466-474.

Nose I, Higashi H, Inokuchi H, Nishi S (1991). Synaptic responses of guinea pig and rat central amygdala neurons in vitro. J Neurophysiol 65: 1227-1241.

O’Dell LE, Sussman AN, Meyer KL, Neisewander JL (1999). Behavioral effects of psychomotor stimulant infusions into amygdaloid nuclei. Neuropsychopharmacology 20: 591-602.

Paxinos G, Watson C (1998). The Rat Brain in Stereotaxic Coordinates, 4th edn. Academic Press: San Diego.

Piazza PV, Deminiere JM, Le Moal M, Simon H (1989). Factors that predict individual vulnerability to amphetamine self-administration. Science 245: 1511-1513.

Piazza PV, Deminiere JM, Maccari S, Le Moal M, Mormede P, Simon H (1991a). Individual vulnerability to drug self-administration: action of corticosterone on dopaminergic systems as a possible pathophysiological mechanism. In: Willner P, 
Scheel-Kruger J (eds). The Mesolimbic Dopamine System: from Motivation to Action. Wiley: New York. pp 473-495.

Piazza PV, Deroche V, Deminiere JM, Maccari S, Le Moal M, Simon H (1993). Corticosterone in the range of stressinduced levels possesses reinforcing properties: implications for sensation-seeking behaviors. Proc Natl Acad Sci USA 90: 11738-11742.

Piazza PV, Le Moal M (1997). Glucocorticoids as a biological substrate of reward: physiological and pathophysiological implications. Brain Res Brain Res Rev 25: 359-372.

Piazza PV, Le Moal M (1998). The role of stress in drug selfadministration. Trends Pharmacol Sci 19: 67-74.

Piazza PV, Rouge-Pont F, Deminiere JM, Kharoubi M, Le Moal M, Simon H (1991b). Dopaminergic activity is reduced in the prefrontal cortex and increased in the nucleus accumbens of rats predisposed to develop amphetamine self-administration. Brain Res 567: 169-174.

Pierre PJ, Vezina P (1997). Predisposition to self-administration amphetamine: the contribution of response to novelty and prior exposure to the drug. Psychopharmacology 129: 277-284.

Rebec GV, Grabner CP, Johnson M, Pierce RC, Bardo MT (1997). Transient increases in catecholaminergic activity in medial prefrontal cortex and nucleus accumbens shell during novelty. Neuroscience 76: 707-714.

Robinet PM, Rowlett JK, Bardo MT (1998). Individual differences in novelty-induced activity and the rewarding effects of novelty and amphetamine in rats. Behav Proc 44: 1-9.
Sanders SK, Shekhar A (1995). Regulation of anxiety by GABAA receptors in the rat amygdala. Pharmacol Biochem Behav 52: 701-706.

Smith Y, Pare D (1994). Intra-amygdaloid projections of the lateral nucleus in the cat: PHA-L anterograde labeling combined with postembedding GABA and glutamate immunocytochemistry. J Comp Neurol 342: 232-248.

Spanis CW, Bianchin MM, Izquierdo I, McGaugh JL (1999). Excitotoxic basolateral amygdala lesions potentiate the memory impairment effect of muscimol injected into the medial septal area. Brain Res 816: 329-336.

Stead JD, Clinton S, Neal C, Schneider J, Jama A, Miller S et al (2006). Selective breeding for divergence in novelty-seeking traits: heritability and enrichment in spontaneous anxietyrelated behaviors. Behav Genet 36: 697-712.

Sun N, Yi H, Cassell MD (1994). Evidence for a GABAergic interface between cortical afferents and brainstem projection neurons in the rat central extended amygdala. J Comp Neurol 340: 43-64.

Wills TA, Vaccaro D, McNamara G (1994). Novelty seeking, risk taking, and related constructs as predictors of adolescent substance abuse: an application of Cloninger's theory. J Subst Abuse 6: 1-20.

Wills TA, Windle M, Cleary SD (1998). Temperament and novelty seeking in adolescent substance abuse: Convergence of dimensions of temperament with constructs from Cloninger's theory. J Pers Soc Psychol 74: 387-406.

Zuckerman M (1994). Behavioral Expressions and Biosocial Bases of Sensation Seeking. Cambridge University Press: Cambridge. 